\title{
Selection of Populations of Puccinia recondita f. sp. tritici for Shortened Latent Period on a Partially Resistant Wheat Cultivar
}

\author{
Jeffrey S. Lehman and Gregory Shaner
}

Department of Botany and Plant Pathology, Purdue University, 1155 Lilly Hall, West Lafayette, IN 47907-1155.

Current address of J. S. Lehman: Department of Life and Earth Sciences, Otterbein College, Westerville, OH 43081.

Accepted for publication 4 November 1996.

\begin{abstract}
Lehman, J. S., and Shaner, G. 1997. Selection of populations of Puccinia recondita $\mathrm{f}$. sp. tritici for shortened latent period on a partially resistant wheat cultivar. Phytopathology 87:170-176.

Wild-type fungal population 851-WT was selected for shortened latent period on cv. CI 13227 for five uredinial generations to study the adaptation of Puccinia recondita f. sp. tritici to partially resistant wheat cultivars. Differences among wild-type and selected populations for traits contributing to parasitic fitness (i.e., latent period, infection frequency, and uredinium area and growth rate) were assessed in monocyclic infection experiments on susceptible cv. Monon and partially resistant cvs. Su-

L-574-1, the selected population was also more fit than the wild-type progenitor for initial uredinium area and growth rate and cumulative urediniospore production. In contrast to wild-type and selected populations on cvs. CI 13227 and L-574-1, selected population 851-C5 on cv. Monon produced slower expanding uredinia with fewer urediniospores than did population 851-WT on Monon. These results show that variation in the latent period of $P$. recondita $\mathrm{f}$. sp. tritici populations is partially under genetic control and wild-type $P$. recondita f. sp. tritici populations contain members reproductively more fit on partially resistant wheat cultivars but not necessarily on susceptible cultivars. Such members are capable of partially overcoming quantitative host resistance.
\end{abstract} won 85, Sw 72469-6, L-574-1, and CI 13227. Differences were greatest among fungal populations on cv. CI 13227. The mean latent period of selected population $851-\mathrm{C} 5$ was 2 days shorter ( 20\%) than that of wildtype population 851-WT. In addition, uredinia of population 851-C5 expanded $40 \%$ faster and produced $\sim 75 \%$ more urediniospores. On cv.
Additional keywords: general, horizontal, race-nonspecific, and ratereducing resistance; leaf rust; reproductive fitness; slow rusting; Triticum aestivum.
The use of genetic resistance is the best approach for control of wheat leaf rust. However, resistance often provides ephemeral protection, because populations of the leaf rust pathogen, Puccinia recondita Roberge ex Desmaz. f. sp. tritici, respond to the selective pressures of resistant host cultivars and produce more virulent phenotypes (33). Because of these changes in the pathogen population, breeding resistant wheat cultivars is a continuing activity (33). Cultivars that provide adequate levels of disease control and have durable resistance (i.e., their resistance remains effective during their prolonged and widespread use in environments favorable for disease) are highly desirable $(7,14)$.

Partially resistant wheat cultivars are suboptimal environments for leaf rust development because they retard the establishment and reproduction of the fungus. The fungus has a longer latent period on partially resistant cultivars than on susceptible cultivars $(27,29$, $37,38)$ and produces smaller uredinia $(29,37,38)$ that contain fewer spores $(27,35,38)$. In addition, the infection frequency of the fungus is often reduced $(27,29,37,38)$. These components of resistance greatly reduce the rate of disease development in the field because $P$. recondita $\mathrm{f}$. sp. tritici is a polycyclic pathogen $(8,13$, 37). Partially resistant cultivars slow, but do not completely inhibit, the spread of leaf rust. Disease is held to levels that are economically less harmful to grain production.

Partial resistance may be more durable than complete resistance because it places less selection pressure on the pathogen and often is genetically more complex than hypersensitivity $(5,13,19,20,21)$. The ability of pathogen populations to respond to the selection

Corresponding author: J. S. Lehman; E-mail address: jlehman@otterbein.edu

Publication no. P-1997-0102-02R

(C) 1997 The American Phytopathological Society pressure of partially resistant wheat cultivars has received very little attention, however.

Selection experiments have been used to demonstrate polygenic variation in traits of nonphytopathogenic fungi, including growth rate in Schizophyllum commune (39), growth rate and spore size in Neurospora crassa $(30,32)$, and penicillin titer in Aspergillus nidulans (26). To a lesser degree, selection experiments have been used to study the variation in parasitic fitness of plant pathogens. By selecting Uromyces appendiculatis, the bean rust fungus, for increased fitness on bean cultivars, Alexander et al. (1) observed slight or no changes in latent period, pustule size, and urediniospore production of the pathogen population. In contrast, Kolmer and Leonard (18) selected fungal populations of Cochliobolus heterostrophus for increased lesion size on corn and demonstrated that the pathogen has the genetic variation to adapt to a partially resistant inbred corn line. In another study, selection was reported to increase the fertility (i.e., perithecial number) of this fungus (17). Kolmer $(15,16)$ conducted selection experiments on $P$. recondita f. sp. tritici with either field collections or sexual populations of rust on wheat cv. Chris (with adult-plant resistance genes $\operatorname{Lr} 13$ and $L r 34$ ) or Roblin (with resistance genes $L r 1, L r 10$, and $L r 13$ ). Kolmer $(15,16)$ found that populations reared for 8 and 12 uredinial generations on cvs. Chris and Roblin, respectively, responded to selection. Selected populations produced more spores per unit area of leaf tissue or were composed of virulence phenotypes in different frequencies relative to the initial population; yet, the cultivars still expressed some degree of resistance.

The likelihood of populations of $P$. recondita $\mathrm{f}$. sp. tritici adapting to partial resistance is difficult to assess. Short of continual evaluation of pathogen diversity on a partially resistant cultivar during wide-scale cultivation in environments favorable for disease, selection experiments may provide the best means of assessing variation in parasitic fitness and of predicting the re- 
sponse of extant populations of $P$. recondita $\mathrm{f}$. sp. tritici toward partial resistance. The objective of this study was to determine whether asexual populations of $P$. recondita f. sp. tritici contain members adapted to partially resistant wheat cultivars. To accomplish this, we repeatedly selected a wild-type population of $P$. recondita f. sp. tritici for shortened latent period on a partially resistant cultivar and quantified pathogen responses to selection.

\section{MATERIALS AND METHODS}

Populations of $\boldsymbol{P}$. recondita f. sp. tritici. Population 851-WT, a naturally occurring Indiana population of $P$. recondita f. sp. tritici, was collected from 200 to 300 uredinia from volunteer seedlings of wheat cv. Beau (CI 17420) on 20 November 1984 at the Purdue Agronomy Farm, West Lafayette, IN. This population was increased for one generation on susceptible cv. Morocco and stored at $-80^{\circ} \mathrm{C}$ until used in selection experiments. Among 24 single-urediniospore isolates from population 851-WT, we detected only pathogen phenotype FBR (with virulence to host resistance genes $L r 2 \mathrm{c}$, $3,3 \mathrm{ka}, 11$, and 30) with the 12 Thatcher isogenic lines in the Prt differential set (25).

In selection experiments, population 851-WT was selected for shortened latent period on partially resistant cv. CI 13227 in the greenhouse. Adaxial surfaces of 20 to 25 newly emerged flag leaves (the uppermost leaf) of 10 to 15 plants of CI 13227 were inoculated with urediniospores of population 851-WT suspended in Soltrol 170 light mineral oil (Philips Petroleum Co., Hennepin, $\mathrm{OK})$. Inoculated plants were misted with water and Tween 20 (water-Tween 20: 1 drop of Tween 20 per liter of $\mathrm{H}_{2} \mathrm{O}$ ) and placed in a moist chamber at 20 to $22^{\circ} \mathrm{C}$ for 12 to $14 \mathrm{~h}$. Uredinia typically erupt from leaf surfaces of cv. CI 13227 over an interval of 6 to 19 days after inoculation; the plot of daily increase in number of uredinia against day after inoculation yields a bell-shaped curve slightly skewed to the right. Because of this distribution of latent period for individual uredinia, urediniospores from early erupting uredinia could be collected separately from those of later erupting uredinia (i.e., truncation selection). After 9 to 11 days, infection sites with short latent periods began to erupt and sporulate, and spores were vacuumed from adaxial leaf surfaces of leaves with a cyclone spore collector (41) attached to a model 13152 Gelman (Ann Arbor, MI) pressure/vacuum pump.

A portion of the spores was stored at $-80^{\circ} \mathrm{C}$ and used to form population $851-\mathrm{C} 1$, the product of one cycle of selection. The remainder of the spores was used to inoculate 20 to 25 flag leaves of 10 to 15 healthy plants of CI 13227 for continued cycles of selection. As uredinia erupted, we repeated the selection process that favored uredinia with short latent periods. In total, population 851-WT was selected for shortened latent period for five asexual generations of the fungus reared on CI 13227 . In the early generations of selection, spores were collected from as few as 100 early erupting uredinia. In later generations, spores were collected from more than 500 uredinia. Populations 851-C1 and 851-C5, which were reared on CI 13227 for one and five asexual generations of selection, respectively, were increased and characterized for fitness on susceptible and partially resistant wheat cultivars along with population 851-WT.

Wheat cultivars. Five cultivars of winter wheat (Triticum aestivum L. em. Thell) were studied, including susceptible cv. Monon (CI 13278) and cvs. Suwon 85 (PI 157600), Sw 72469-6 (Strampelli/69D-3607//Chokwang), L-574-1 (Wakeland/Blueboy), and CI 13227 (Wabash/American Banner//Klein Anniversario), which were previously reported to be partially resistant $(22,24,29,37)$.

Seedlings were vernalized at $3^{\circ} \mathrm{C}$ for 6 to 8 weeks under $12 \mathrm{~h}$ of fluorescent light per day and transplanted individually in $400-\mathrm{ml}$ plastic pots containing a soil-peat mixture. Natural daylight in the greenhouse was supplemented with incandescent and fluorescent light for $16 \mathrm{~h} /$ day $\left(\sim 200 \mu \mathrm{E} \mathrm{m}^{-2} \mathrm{~s}^{-1}\right)$ from the time of transplanting to maturity. Day and night temperatures were 20 to 24 and 17 to $20^{\circ} \mathrm{C}$, respectively.

Measurements of components of parasitic fitness and host resistance. Six traits that characterize partial host resistance and parasitic fitness were measured in monocyclic infection experiments (experiments I, II, and III) conducted during March 1989, November 1990, and April 1991, respectively. In experiment I, newly emerged flag leaves of each of the five cultivars were inoculated with separate suspensions of populations 851-WT, 851-C1, and $851-\mathrm{C} 5$ in concentrations of $20 \mathrm{mg}$ of spores per $30 \mathrm{ml}$ of waterTween 20 with a model 151 Devilbiss (Somerset, PA) atomizer. In experiments II and III, the adaxial surfaces of flag leaves were inoculated in a spore-settling tower (11) along with four plates of $1.5 \%$ water agar. We estimated a deposition of two to three viable spores per $\mathrm{mm}^{2}$ of flag leaf based on spore density and percent germination observed on the agar. For all experiments, inoculated plants were misted with water-Tween 20 and placed in a moist chamber at 20 to $22^{\circ} \mathrm{C}$ for 12 to $14 \mathrm{~h}$.

In experiment I, uredinia on the whole leaf were counted on days 7 to 20 after inoculation. In experiments II and III, uredinia on only a portion of the flag leaf, typically the middle 3 to $5 \mathrm{~cm}$, were counted each day. Mean latent period (MLP), the average time required for uredinia to erupt, was calculated from uredinial counts taken on days 7 to 20 after inoculation based on the equation

$$
M L P=\sum_{i=0}^{n} P_{i} t_{i}
$$

in which $P_{i}$ is the proportion of uredinia relative to the final number of uredinia that appear on the $i$ th day after inoculation, $t_{i}$ is the $i$ th day after inoculation, and $n$ is the number of days after inoculation when all uredinia have appeared.

In experiments II and III, five arbitrarily selected uredinia for each population on individual flag leaves of each cultivar were marked, and every 2 to 4 days throughout the expansion of these lesions, their length (L) and width (W) were measured to the nearest tenth of a millimeter with a Bausch \& Lomb (Rochester, NY) measuring magnifier. From these dimensions, uredinial area (UA) was calculated using the equation for the area of an ellipse: $U A=$ $(L)(W)(3.14) / 4$.

Uredinial area was regressed on day after inoculation, and rates of uredinial growth, the slopes of the regression line, were calculated. Regression equations with coefficients of determination $<0.70$ were excluded from analyses of uredinial growth rate.

In experiments II and III, infection frequency (IF), defined as the proportion of viable urediniospores applied per square millimeter of leaf tissue that give rise to uredinia, was calculated using the equation

$$
\begin{gathered}
I F=\left(\text { no. of uredinia } / \mathrm{mm}^{2} \text { of leaf tissue) } /\right. \\
\text { (no. of viable spores applied } / \mathrm{mm}^{2} \text { leaf tissue) }
\end{gathered}
$$

Urediniospore production in experiments II and III also was measured. In experiment II, spores were collected from five individual, isolated uredinia on days 10, 14, 19, 21, and 27 after inoculation with a modification of the spore collector described by Shaner (34). Our collector differed in that (i) the main body was constructed from a $3 \times 16-\mathrm{cm}$ acrylic tube; (ii) suction was provided by a 60 -ml rubber suction bulb; and (iii) the silicon-coated microscope slide was movable within the collector body. Once collected on greased slides, images of the spores were displayed on a video monitor connected to a microscope, and manually counted with a digitizing pen and the Interactive Counting Program of the LeMont Oasys Image Analyses System (State College, PA). Cumulative urediniospore production was calculated by averaging the five estimates of spore production per uredinium for the same leaf and totaling these averages for the five collection days.

In experiment III, spores were collected from 10 to 216 uredinia on individual flag leaves on days 9, 11, 13, 15, 19, and 21 after inoculation. Before uredinia erupted, a 3 or $5 \mathrm{~cm}$ length of the flag 
leaf was marked, and the spores produced from erupted uredinia were collected with a small cyclone collector (41). Spores were suspended in $10 \mathrm{ml}$ of phosphate-buffered saline with $0.5 \%$ Tween 20. Spores in a 500-ml sample were counted with a model FN Coulter counter (Coulter Electronic, Inc., Hialeah, FL). The average number of spores per uredinium was calculated by dividing the total number of spores by the number of uredinia present on a given collection day. The means for the six collection days were totaled to calculate cumulative urediniospore production.

Experimental design and statistical analysis. Each experiment was a factorial design with five cultivars, three isolates, and four or five replications. Because the number of replications within experiments varied, analyses were performed on means for each cultivar-isolate combination averaged across replications within experiments (i.e., unweighted means analyses) $(9,28)$. The linear additive model for the unweighted means analyses was

$$
Y_{i j k}=\mu+L_{i}+C_{j}+L C_{i j}+P_{k}+L P_{i k}+C P_{j k}+L C P_{i j k}
$$

in which $Y_{i j k}$ is the response of the $i j k$ th individual subunit; $\mu$ is the overall mean; $L_{i}$ is the effect of the $i$ th experiment, $i=1, \ldots, 3$ experiments for latent period and $i=1$ or 2 experiments for analyses of other components; $C_{j}$ is the effect of the $j$ th wheat cultivar, $j=1, \ldots, 5$ cultivars; $L C_{i j}$ is the interaction effect of the $i$ th experiment with $j$ th cultivar; $P_{k}$ is the effect of the $k$ th fungal population, $k=1, \ldots, 3$ populations of $P$. recondita f. sp. tritici; $L P_{i k}$ is the interaction effect of the $i$ th experiment with the $k$ th population; $C P_{j k}$ is the interaction effect of the $j$ th cultivar with the $k$ th population; and $L C I_{i j k}$ is the experimental error of unweighted mean values $\left(E_{\mu}\right)$. The expected mean squares are given in Table 1 .

A $\log _{10}$ transformation of mean latent period and cumulative urediniospore production and an arcsine transformation of $(I F)^{1 / 2}$ effectively eliminated the association between mean and variance that existed for untransformed statistics (40). Values for initial and final uredinial area and for uredinial growth rate were expressed as a proportion of the values for $\mathrm{cv}$. Monon inoculated with 851-WT, and untransformed data were analyzed. Duncan's new multiple range test $(\alpha=0.05)$ was used to separate means for cultivars, populations, and interactions (40). The coefficient of variation $(C V)$ also was calculated for the analysis of variance for each fitness-resistance component with the equation $C V=(100 s / Y)$ percent, where $s$ is the sample standard deviation and $Y$ is the sample mean for components (40).

\section{RESULTS}

The infection types of uredinia for all isolates on flag leaves of each cultivar indicated a compatible interaction. This shows that

TABLE 1. Expected mean squares (EMS) of the unweighted means analyses of components of parasitic fitness and host resistance for Puccinia recondita f. sp. tritici on Triticum aestivum

\begin{tabular}{llll}
\hline $\begin{array}{l}\text { Source of } \\
\text { variation }\end{array}$ & \multicolumn{1}{c}{$\mathrm{df}^{\mathrm{y}}$} & \multicolumn{1}{c}{$\mathrm{EMS}^{\mathrm{z}}$} & \multicolumn{1}{c}{ Error term } \\
\hline Experiment $\left(L_{i}\right)$ & $e-1$ & & \\
Cultivar $\left(C_{j}\right)$ & $c-1$ & $\sigma_{e}^{2} / r_{h}+r \sigma_{L C}{ }^{2}+l i \phi_{C}$ & $\sigma_{e}^{2} / r_{h}+r \sigma_{L C}{ }^{2}$ \\
$L C_{i j}$ & $(e-1)(c-1)$ & $\sigma_{e}^{2} / r_{h}+r \sigma_{L C}$ & $\sigma_{e}^{2} / r_{h}$ \\
Population $\left(P_{k}\right)$ & $p-1$ & $\sigma_{e}^{2} / r_{h}+c \sigma_{L P}+l c \phi_{i}$ & $\sigma_{e}^{2} / r_{h}+c \sigma_{L P}{ }^{2}$ \\
$L P_{i k}$ & $(e-1)(p-1)$ & $\sigma_{e}^{2} / r_{h}+c \sigma_{L P}$ & $\sigma_{e}^{2} / r_{h}$ \\
$C P_{j k}$ & $(c-1)(p-1)$ & $\sigma_{e}^{2} / r_{h}+\sigma_{L C P}+l \phi_{C P}$ & $\sigma_{e}^{2} / r_{h}+\sigma_{L C P}$ \\
$L C P_{i j k}\left(\operatorname{error} E_{\mu}\right)$ & $(e-1)(c-1)$ & & \\
& $(p-1)$ & $\sigma_{e}^{2} / r_{h}+\sigma_{L C P}$ & $\sigma_{e}^{2} / r_{h}$ \\
\hline
\end{tabular}

${ }^{x}$ Sources of variation in the linear additive model are explained in text.

${ }^{y}$ Letters $e, c$, and $p$ refer to the number of levels of experiments, cultivars, and populations, respectively.

${ }^{\mathrm{z}}$ Variance components $\left(\sigma^{2}\right)$ are for experiment $\times$ cultivar $(L C)$, experiment $\times$ population $(L P)$, and experiment $\times$ cultivar $\times$ population $(L C P)$. Variance component $\sigma_{e}{ }^{2}$ is for the pooled errors from experiments I, II, and III. $r_{h}$ is the harmonic mean of the number of replications in experiments I, II, and III. Fixed effects $(\phi)$ are for cultivar $(C)$, population $(P)$, and cultivar $\times$ population $(C P)$. the cultivars we studied lacked effective genes for hypersensitive resistance in the adult plant stage.

Coefficients of variation, mean-corrected measures of error variance, were used to compare the precision of experiments involving the different components independent of unit of measure. Coefficients of variation for $\log _{10}$ cumulative urediniospore production, $\log _{10}$ mean latent period, uredinial growth rate, initial uredinial area, final uredinial area, and arcsine $(I F)^{1 / 2}$ were $1.4,3.3$, $7.1,11.9,17.6$, and $24.5 \%$, respectively.

Differences in latent period. Populations differed significantly for mean latent period $(P=0.043)$. The latent period of population 851-C5 was shorter than that of 851-WT or 851-C1 (Fig. 1). There was no difference between the latent periods of populations 851WT and 851-C1.

Differences in latent period among cultivars were significant $(P=$ 0.006). Cv. Monon had the shortest latent period; cvs. CI 13227, Suwon 85, and Sw 72469-6 had the longest mean latent periods; and cv. L-574-1 was intermediate (Fig. 1). Latent periods of CI 13227, Suwon 85, Sw 72469-6, and L-574-1 were 3.6, 3.3, 2.6, and 1.7 days or $49,44,33$, and $23 \%$ longer, respectively, than the latent period of Monon.

The cultivar $\times$ pathogen population interaction was nonsignificant $(P=0.50)$; however, Duncan's new multiple range test indicated that the latent period of population 851-C5 on CI 13227 was significantly shorter than the latent periods of population 851-WT or 851-C1 only on CI 13227 (Fig. 2). Despite this shortening, the latent period of 851-C5 on CI 13227 was still longer than the latent period of any isolate on Monon. There were no differences in latent period among the three populations on any of the other cultivars.

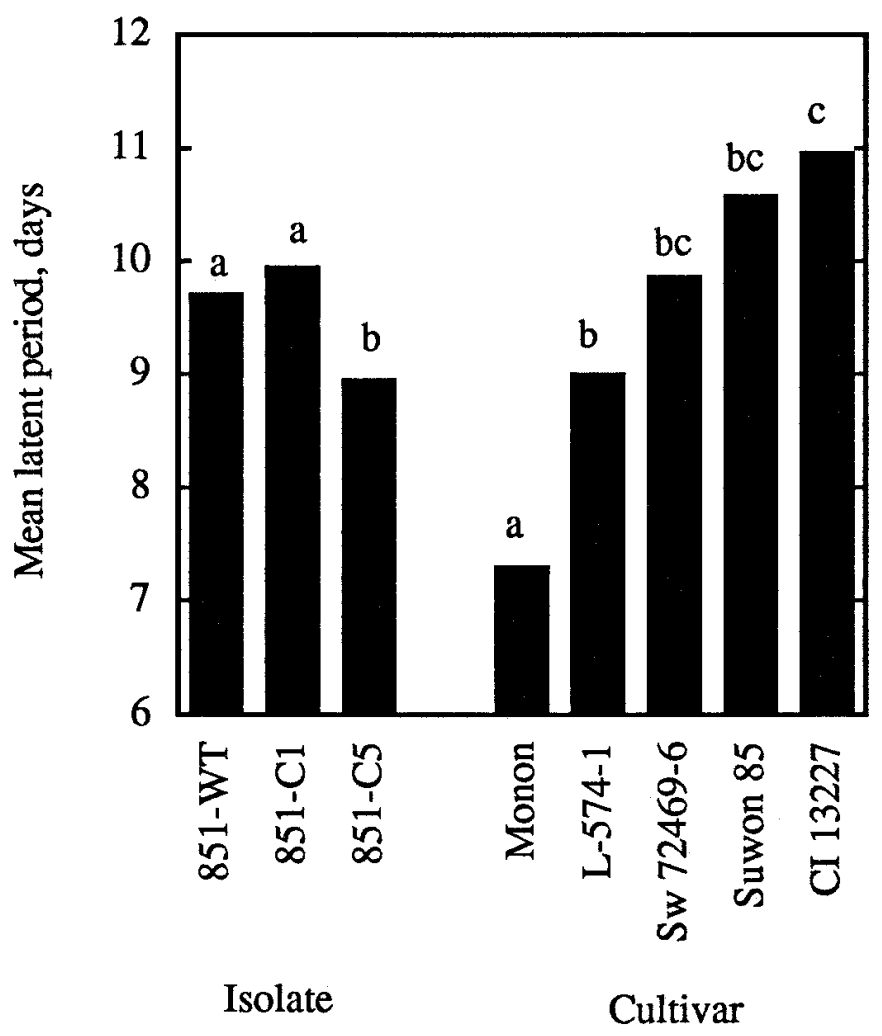

Fig. 1. Mean latent period for flag leaves of Triticum aestivum inoculated with three populations of Puccinia recondita f. sp. tritici. Mean latent period is the weighted mean number of days from infection to production of secondary inoculum (details given in text). Each bar represents the unweighted mean of three experiments, with four or five replications averaged across three populations of $P$. recondita $\mathrm{f}$. sp. tritici or five wheat cultivars. Cultivar or population means with a letter in common above the bar do not differ significantly for log-transformed data according to Duncan's new multiple range test $(\alpha=0.05)$. 
The difference between the mean latent period for 851-WT on Monon and 851-WT on CI 13227 was 4.3 days (Fig. 2). This difference represents the total resistance for latent period of CI 13227 , because the latent period of wild-type pathogen populations on Monon, previously reported as susceptible (24), reflects the response of cultivars with little resistance for this trait. The difference between 851-C5 on CI 13227 and 851-WT on Monon was 2.3 days and represents the resistance remaining in CI 13227 (53\%) after selection of $P$. recondita f. sp. tritici on CI 13227. Thus, population 851-C5 overcame $47 \%$ of the resistance to latent period present in CI 13227.

Differences in infection frequency. Pathogen population was not a significant source of variation in the analysis of arcsine $(I F)^{1 / 2}$ $(P=0.87)$, and there were no differences among populations for infection frequency. The infection frequency for cv. CI 12337 (0.05 uredinia per germinated urediniospore) was lower than that for Monon (0.12 uredinia per germinated urediniospore). The other cultivars were not different than Monon.

TABLE 2. Uredinium area (UA) ${ }^{v}$, uredinium growth (UG) rate, and urediniospore production (UP) for adult plants of five wheat cultivars inoculated with three populations of Puccinia recondita f. sp. tritici

\begin{tabular}{lcccc}
\hline & $\begin{array}{c}\text { Relative UA } \\
\text { (initial) }^{\mathrm{w}}\end{array}$ & $\begin{array}{c}\text { Relative UA } \\
\text { (final) }^{\mathrm{x}}\end{array}$ & $\begin{array}{c}\text { Relative UG } \\
\text { rate }^{\mathrm{y}}\end{array}$ & $\begin{array}{c}\text { Cumulative } \\
\text { UP }^{\mathrm{z}}\end{array}$ \\
\hline \multicolumn{2}{l}{ Pathogen population } & & & \\
$\quad$ 851-WT & 0.71 & 0.70 & 0.69 & 5,589 \\
851-C1 & 0.72 & 0.72 & 0.70 & 5,212 \\
851-C5 & 0.80 & 0.68 & 0.73 & 5,847 \\
Wheat cultivar & & & & \\
$\quad$ Monon & $0.91 \mathrm{~b}$ & $0.97 \mathrm{~b}$ & $0.96 \mathrm{~b}$ & $9,968 \mathrm{~b}$ \\
L 574-1 & $0.91 \mathrm{~b}$ & $0.94 \mathrm{~b}$ & $1.00 \mathrm{~b}$ & $7,540 \mathrm{~b}$ \\
Suwon 85 & $0.59 \mathrm{a}$ & $0.60 \mathrm{a}$ & $0.59 \mathrm{a}$ & $4,099 \mathrm{a}$ \\
Sw 72469-6 & $0.68 \mathrm{a}$ & $0.44 \mathrm{a}$ & $0.39 \mathrm{a}$ & $3,015 \mathrm{a}$ \\
CI 13227 & $0.65 \mathrm{a}$ & $0.56 \mathrm{a}$ & $0.57 \mathrm{a}$ & $3,124 \mathrm{a}$ \\
\hline
\end{tabular}

${ }^{v} \mathrm{UA}$ (initial and final) was calculated using the equation $U A=(L)(W)(3.14) / 4$, in which $L$ and $W$ are uredinium length and width, respectively.

${ }^{\mathrm{w}}$ Initial UA was expressed as a proportion of the UA for population 851-WT on cv. Monon $\left(0.128 \mathrm{~mm}^{2}\right)$. Each value for the pathogen populations is the unweighted mean of two experiments, with four or five replications averaged across wheat cultivars. For populations of $P$. recondita f. sp. tritici, mean initial UAs did not differ. Each value for wheat cultivars is the unweighted mean of two experiments, with four or five replications averaged across populations of $P$. recondita $\mathrm{f}$. sp. tritici. Within columns, cultivar means with a letter in common are not significantly different according to Duncan's new multiple range test $(\alpha=0.05)$.

${ }^{x}$ Final UA was expressed as a proportion of the UA for population 851-WT on cv. Monon $\left(0.545 \mathrm{~mm}^{2}\right)$. Each value for pathogen populations is the unweighted mean of two experiments, with four or five replications averaged across wheat cultivars. For populations of $P$. recondita f. sp. tritici, mean final UAs do not differ. Each value for wheat cultivars is the unweighted mean of two experiments, with four or five replications averaged across populations of $P$. recondita $\mathrm{f}$. sp. tritici. Within columns, cultivar means with a letter in common are not significantly different according to Duncan's new multiple range test $(\alpha=0.05)$.

y UG rate was calculated from the regression of UA on day after inoculation (details are given in text) and expressed as a proportion of the UG rate for population $851-\mathrm{WT}$ on $\mathrm{cv}$. Monon $\left(0.06 \mathrm{~mm}^{2} / \mathrm{day}\right)$. Each value for pathogen populations is the unweighted mean of two experiments, with four or five replications averaged across wheat cultivars. For populations of $P$. recondita f. sp. tritici, mean relative UG rates do not differ. Each value for wheat cultivars is the unweighted mean of two experiments, with four or five replications averaged across populations of $P$. recondita $\mathrm{f}$. $\mathrm{sp}$. tritici. Within columns, cultivar means with a letter in common are not significantly different according to Duncan's new multiple range test $(\alpha=0.05)$.

${ }^{z}$ Cumulative UP is the cumulative number of spores per uredinium produced at five or six samplings between 9 and 27 days after inoculation. Each value for pathogen populations is the unweighted mean of two experiments, with four or five replications averaged across wheat cultivars. For populations of $P$. recondita f. sp. tritici, production of urediniospores does not differ. Each value for wheat cultivars is the unweighted mean of two experiments, with four or five replications averaged across populations of $P$. recondita f. sp. tritici. Within columns, cultivar means with a letter in common are not significantly different according to Duncan's new multiple range test $(\alpha=0.05)$.
Differences in uredinium area and growth rate. Cultivar, but not pathogen population, was a significant source of variation in the analysis of initial and final uredinium area and uredinium growth rate $(P=0.05$ to 0.0043$)$. Averaged across populations, values for these traits were the same for cvs. Monon and L-574-1 and significantly larger than those for cvs. CI 13227, Sw 72469-6, and Suwon 85 (Table 2). There were no differences among populations averaged across cultivars (Table 2).

For initial uredinium area (Fig. 3) and uredinium growth rate (Fig. 4), population 851-C5 on cvs. CI 13227 and L-574-1 had significantly larger values than the wild-type population. In contrast, values for uredinium growth rate for population 851-C5 on Monon were less than for 851-WT on this cultivar (Fig. 4). Uredinium growth rates were the same for populations 851-WT and 851-C5 on Sw 72469-6, but uredinia of population 851-C1 grew significantly faster. For final uredinium area, there were no differences among populations on individual cultivars.

Differences in sporulation. Differences among cultivars for cumulative urediniospore production were significant $(P=0.008)$. Cv. L-574-1 produced as many spores as Monon, but cvs. Sw 72469-6, Suwon 85, and CI 13227 produced fewer spores (Table 2). Differences among populations averaged across cultivars were nonsignificant.

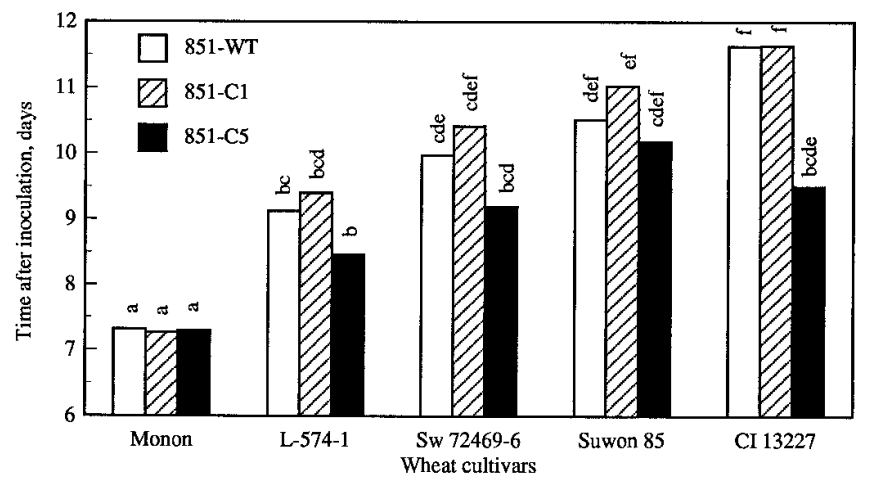

Fig. 2. Unweighted means for mean latent period for flag leaves of Triticum aestivum inoculated with three populations of Puccinia recondita f. sp. trit$i c i$. Mean latent period is the weighted mean number of days from infection to production of secondary inoculum (details given in text). Each bar is the unweighted mean of three experiments, with four or five replications for cultivar-population combinations. Combination means with a letter in common above the bar do not differ significantly for log-transformed data according to Duncan's new multiple range test $(\alpha=0.05)$.

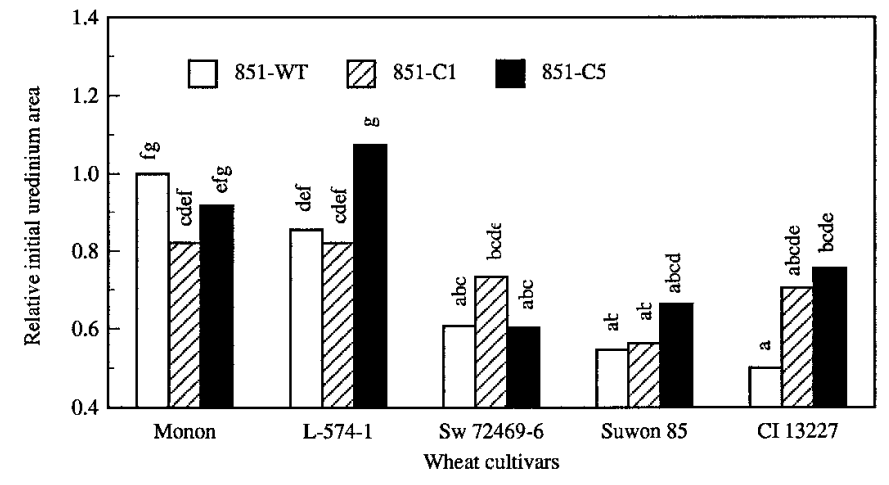

Fig. 3. Unweighted means for relative initial uredinium area (UA) for flag leaves of Triticum aestivum inoculated with three populations of Puccinia recondita $\mathrm{f}$. sp. tritici. UA is calculated based on the equation $U A=(L)(W)$ (3.14)/4, where $L$ and $W$ are uredinial length and width, respectively. UA is expressed as a proportion of the UA of population 851-WT on cv. Monon $\left(0.128 \mathrm{~mm}^{2}\right)$. Each bar is the unweighted mean of two experiments, with four or five replications for cultivar-population combinations. Combination means with a letter in common above the bar do not differ significantly according to Duncan's new multiple range test $(\alpha=0.05)$. 


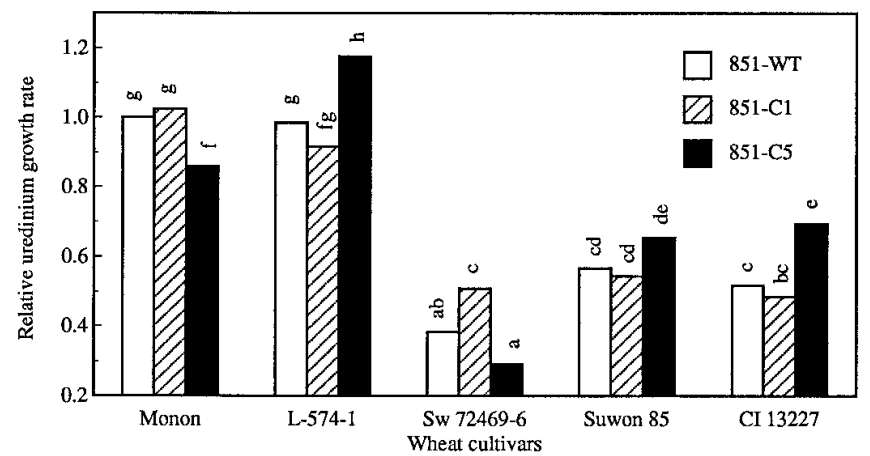

Fig. 4. Unweighted means for relative uredinium growth rate for flag leaves of Triticum aestivum inoculated with three populations of Puccinia recondita f. sp. tritici. Uredinium growth rate is calculated based on the regression of uredinium area on day after inoculation (details given in text) and expressed as a proportion of the uredinium growth rate of population $851-\mathrm{WT}$ on $\mathrm{cv}$. Monon $(0.06 \mathrm{~mm} /$ day $)$. Each bar is the unweighted mean of two experiments, with four or five replications for cultivar-population combinations. Combination means with a letter in common above the bar do not differ significantly according to Duncan's new multiple range test $(\alpha=0.05)$.

The cultivar $\times$ isolate interaction was significant $(P=0.0041)$ for cumulative urediniospore production. Population 851-C5 on CI 13227 produced more spores than did populations 851-WT and 851-C1 (Fig. 5). Despite these increases in sporulation, population 851-C5 on CI 13227 produced fewer spores than any population on Monon. Population 851-C5 on L-574-1 produced more spores than did $851-W T$ but no more than $851-\mathrm{C} 1$. Spore production by 851-WT and 851-C1 on L-574-1 were the same. On Monon, population 851-C5 produced fewer spores than 851-WT. However, spore production for population $851-\mathrm{WT}$ and $851-\mathrm{C} 1$ on Monon were the same. On Sw 72469-6, selected populations produced the same amount of spores as did population 851-WT.

The difference between spore production for 851-WT on Monon and 851-WT on CI 13227 was 9,234 spores and represents the total resistance of CI 13227 for this component of resistance (Fig. 5). The difference between 851-C5 on CI 13227 and 851-WT on Monon was 7,371 spores and represents the resistance remaining (80\%) after selection on CI 13227. Selected population 851-C5 overcame $20 \%$ of CI 13227's resistance for sporulation. Similarly, population 851-C5 adapted to overcome $45 \%$ of the resistance of L-574-1.

\section{DISCUSSION}

For polycyclic plant pathogens, the time required to produce offspring and the number and survivability of offspring influence population fitness. Individuals with short latent periods produce offspring earlier, allowing additional cycles of infection, which results in faster rates of disease development. Because of the correlation between latent period and disease development in the field $(4,23,37)$, knowledge of variation in latent period for populations of $P$. recondita $\mathrm{f}$. sp. tritici on partially resistant wheat cultivars and the response of these populations to selection should be useful in predicting durability of host resistance. We previously observed that 42 to $49 \%$ of the variation in latent period between singleuredinial isolates on partially resistant cv. CI 13227 was under genetic control (24). In addition, there was evidence to suggest that gene(s) governing latent period in CI 13227 interacted specifically with gene(s) governing latent period in the pathogen. These results suggest that natural selection should operate in favor of increased parasitic fitness. As a result, partial resistance for latent period may be rendered increasingly less effective.

Not all fitness and resistance components were measured with equal precision. Analyses of cumulative urediniospore production and mean latent period could detect smaller differences in parasitic fitness between wild-type and selected populations than analyses of other fitness components. However, it takes more time to collect latent period and sporulation data than to collect data for infection frequency and uredinium area and growth rate. Although measurements of initial uredinium area and growth rate are not as precise as those for mean latent period or cumulative urediniospore production, they may be useful if large numbers of pathogen isolates are to be screened or if differences between populations are large. Measurements of infection frequency lacked precision and were not useful in characterizing the fitness of $P$. recondita f. sp. tritici populations. Similar observations have been reported by others $(3,6,31)$.

The error associated with certain components of parasitic fitness and host resistance is not necessarily an inherent feature of the component. Large coefficients of variation for the analysis of arcsine $(I F)^{1 / 2}$ could be due to the method by which spores were deposited on leaves. In the spore-settling tower (11), spores "settle out" on the inoculation table in nonuniform patterns. Four plates of water agar were placed in the tower for each inoculation to estimate the distribution of spores across the table, and they revealed that spore distributions were uneven, which precluded an accurate estimate of spore deposition on each leaf. In addition, the inevitable "spotty" misting of flag leaves during the 12- to 14-h moist period after inoculation could reduce precision. High coefficients of variation for the analyses of initial and final uredinium area and growth rate may be due to the fusion of uredinia as they expand or to the formation of satellite rings of uredinia surrounding aging primary uredinia. Neither occurrence allows precise measurement of uredinium length and width, which were used in calculations of uredinium area. These problems tend to be greater for older uredinia and could explain the higher coefficient of variation of final uredinium area relative to that of initial uredinium area. Because uredinium growth rate was calculated from regression analyses in which regression equations with coefficients of determination $<0.70$ were excluded, it is not surprising that coefficients of variation for uredinium growth rate were lower than those for initial and final uredinium area.

Based on response to selection, the variation in latent period of population 851-WT on CI 13227 appears to be partially under genetic control. Because the intensity of selection or the selection differential was unknown, heritability of latent period could not be calculated from the response to selection (12). Because populations responded to selection, a portion of the variation in latent period between isolates of $P$. recondita $\mathrm{f}$. $\mathrm{sp}$. tritici must be genetic. Selection for five asexual generations on CI 13227 resulted in the pathogen population overcoming $47 \%$ of the resistance for latent period in CI 13227; $53 \%$ of the resistance was still effective.

CI 13227 appears to have four genes of unequal effects and with epistasis that control latent period (36). Analysis of $F_{7}$ families of a recombinant inbred population indicated that genotypes that carried the plus allele for long latent period at the locus with the greatest effect had an average latent period that was $35 \%$ longer than the latent periods of genotypes with the opposite allele. If selection for greater fitness in the pathogen led to genotypes of $P$. recondita $\mathrm{f}$. $\mathrm{sp}$. tritici that overcame the effects of this one gene, they would reduce the mean latent period on CI 13227 from about 12.5 days to 9.2 days according to this model. If a gene at one of the other three loci is overcome by the pathogen, this would reduce mean latent period from 12.5 to from 10.6 to 11.7 days, depending on the particular locus, which is about the magnitude of reduction in mean latent period we observed after five cycles of selection. The partial adaptation toward resistance for latent period in CI 13227 may be due to the absence of individuals with genotypes that allow them to overcome all four genes controlling latent period in CI 13227 (i.e., individuals favored in selection only had greater fitness toward the minor gene). The genes controlling latent period in CI 13227 may include host $\mathrm{Lr}$ genes for resistance to leaf rust. CI 13227 has Klein Anniversario, an Argentine wheat, in its pedigree. Klein Anniversario carries resistance gene Lr3ka and may carry gene Lr34 (2). CI 13227 may have inherited Lr34, 
which may contribute to its increased latent period. Drijepondt and Pretorius (10) demonstrated that the latent period of $P$. recondita f. sp. tritici on wheat line RL6058 with $\operatorname{Lr34}$ was 2.2 to 2.7 days longer than on susceptible cv. Thatcher. Kolmer $(15,16)$ found that populations repeatedly exposed to cultivars with adult-plant resistance genes $\operatorname{Lr} 13$ and $L r 34$ produced more spores per unit area of leaf tissue and were composed of virulent phenotypes in different frequencies compared to unselected populations; yet, the cultivars still expressed some degree of resistance.

Although selection was for decreased latent period, population 851-C5 on cvs. CI 13227 and L-574-1 produced more spores than did population $851-\mathrm{WT}$ on these cultivars, but it produced fewer spores than 851-WT on cv. Monon. Increased sporulation of population 851-C5 on CI 13227 could be due to pleiotropic effects of the genes controlling latent period or linkage between the genes controlling latent period and sporulation.

Selection for shorter latent period on CI 13227 also changed sporulation on L-547-1 and Monon. These changes could be the result of epistasis or linkage. The fact that population 851-C5 sporulated $22 \%$ less on Monon than did 851-WT suggests that if a diversity of partially resistant wheat cultivars were grown in a region, adaptation to one might be offset by reduction in fitness on another. This would stabilize the pathogen population and contribute to the durability of resistance.

The differences in initial uredinium area and growth rate between populations 851-WT and 851-C5 on CI 13227 and L-574-1 were likely due to factors discussed for sporulation (i.e., pleiotropy or linkage). On cvs. Monon and Sw 72469-6, uredinia of selected populations $851-\mathrm{C} 5$ or $851-\mathrm{C} 1$ grew slower than those of population 851-WT. The response of populations on Monon can be explained by linkage in repulsion for uredinium growth rate in different cultivars. For Sw 72469-6, the response does not parallel selection. Uredinia of population $851-\mathrm{C} 1$ grew faster than uredinia of 851-WT, but uredinia of 851-C5 did not. These results imply that $P$. recondita f. sp. tritici genotypes that have short latent periods on CI 13227 show considerable variation for uredinium growth rate on $\mathrm{Sw} 72469-6$.

Our research shows that wild-type populations of $P$. recondita $\mathrm{f}$. sp. tritici contain members capable of overcoming to some degree the partial resistance of some wheat cultivars. The question of the durability of partial resistance, therefore, depends on the intensity of natural selection. If natural selection is mild, the frequency of individuals capable of overcoming partially resistant hosts would remain unchanged or be altered only slightly. If natural selection is intense, frequencies of more fit members should increase and render at least part of the resistance ineffective. However, individuals selected from a wild-type population on one cultivar may have greater or lower fitness on other partially resistant cultivars. Further, given that selection in the field may not be as severe as our selection procedure, pathogen populations could retain a high level of polymorphism to partially resistant cultivars, perhaps showing only locally increased fitness on specific cultivars.

\section{ACKNOWLEDGMENTS}

This research was supported in part by a grant from Public Varieties Indiana, Inc., and the Purdue Research Foundation. Purdue Agricultural Experiment Station Journal Paper 14978.

\section{LITERATURE CITED}

1. Alexander, H. M., Groth, J. V., and Roelfs, A. P. 1985. Virulence changes in Uromyces appendiculatus after five asexual generations on a partially resistant cultivar of Phaseolus vulgaris. Phytopathology 75:449-453.

2. Anderson, R. G. 1963. Studies on the inheritance of resistance to leaf rust of wheat. Pages 144-155 in: Proceedings of the 2nd International Wheat Genetics Symposium.

3. Broers, L. H. M. 1989. Influence of development stage and host genotype on three components of partial resistance to leaf rust in spring

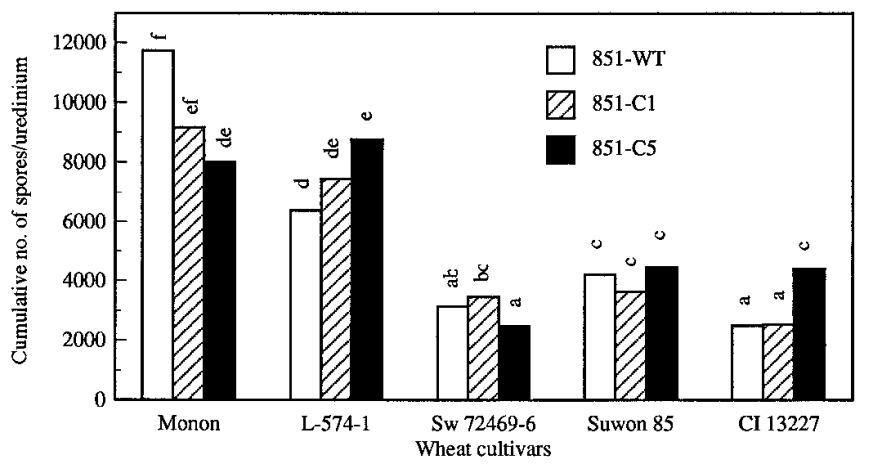

Fig. 5. Unweighted means for cumulative urediniospore production for flag leaves of Triticum aestivum inoculated with three populations of Puccinia recondita $\mathrm{f}$. sp. tritici. Cumulative urediniospore production is the cumulative number of spores per uredinium produced on five or six samplings between 9 and 27 days after inoculation. Each bar is the unweighted mean of two experiments, with four or five replications for cultivar-population combinations. Combination means with a letter in common above the bar do not differ significantly for log-transformed data according to Duncan's new multiple range test $(\alpha=0.05)$.

wheat. Euphytica 44:187-189.

4. Broers, L. H. M. 1989. Partial resistance to wheat leaf rust in 18 spring wheat cultivars. Euphytica 44:247-258.

5. Broers, L. H. M., and Jacobs, T. 1989. The inheritance of host plant effect on latency period of wheat leaf rust in spring wheat. II. Number of segregating factors and evidence for transgressive segregation in $\mathrm{F}_{3}$ and $\mathrm{F}_{5}$ generations. Euphytica 44:207-214.

6. Broers, L. H. M., and Lopez-Atilano, R. M. 1994. A method of inoculating adult wheat plants with urediospores of Puccinia striiformis to measure components of resistance. Plant Dis. 78:353-357.

7. Caldwell, R. M. 1968. Breeding for general and/or specific resistance. Pages 263-272 in: Proc. 3rd Int. Wheat Genet. Symp. Australian Academy of Science, Canberra.

8. Caldwell, R. M., Roberts, J. J., and Eyal, Z. 1970. General resistance ("slow rusting") to Puccinia recondita f. sp. tritici in winter and spring wheats. (Abstr.) Phytopathology 60:1287.

9. Cochran, W. G., and Cox, G. M. 1957. Experimental Designs. 2nd ed. John Wiley \& Sons, New York.

10. Drijepondt, S. C., and Pretorius, Z. A. 1989. Greenhouse evaluation of adult-plant resistance conferred by the gene Lr34 to leaf rust of wheat. Plant Dis. 73:669-671.

11. Eyal, Z., Clifford, B. C., and Caldwell, R. M. 1968. A settling tower for quantitative inoculation of leaf blades of mature small grain plants with urediniospores. Phytopathology 58:530-531.

12. Falconer, D. S. 1989. Introduction to quantitative genetics. Longman, Inc., London.

13. Gavinlertvatana, S., and Wilcoxson, R. D. 1978. Inheritance of slow rusting of spring wheat by Puccinia recondita f. sp. tritici and host parasite relationships. Trans. Br. Mycol. Soc. 71:413-418.

14. Johnson, R. 1984. A critical analysis of durable resistance. Annu. Rev. Phytopathol. 22:309-330.

15. Kolmer, J. A. 1990. Selection of virulence phenotypes in a heterogeneous, asexual population of Puccinia recondita f. sp. tritici. Phytopathology 80:1377-1381.

16. Kolmer, J. A. 1993. Selection in a heterogeneous population of Puccinia recondita $\mathrm{f}$. sp. tritici. Phytopathology 83:909-914.

17. Kolmer, J. A., and Leonard, K. J. 1985. Genetic variation and selection for fertility in the fungus Cochliobolus heterostrophus. Heredity 55:335339.

18. Kolmer, J. A., and Leonard, K. J. 1986. Genetic selection and adaptation of Cochliobolus heterostrophus to corn hosts with partial resistance. Phytopathology 76:774-777.

19. Kuhn, R. C., Ohm, H. W., and Shaner, G. E. 1980. Inheritance of slow leaf-rusting resistance in Suwon 85 wheat. Crop Sci. 20:655-659.

20. Lee, T. S. 1983. Genetics and histology of slow leaf-rusting resistance in wheat. Ph.D. thesis. Purdue University, West Lafayette, IN.

21. Lee, T. S., and Shaner, G. 1985. Oligogenic inheritance of length of latent period in six slow leaf-rusting wheat cultivars. Phytopathology 75: 636-643

22. Lehman, J. S., and Shaner, G. E. 1990. Adaptation of Puccinia recondita to slow-rusting wheat cultivars due to artificial selection. (Abstr.) Phytopathology 80:999.

23. Lehman, J. S., and Shaner, G. 1992. Correlation between pathogen fit- 
ness components and epidemics of wheat leaf rust. (Abstr.) Phytopathology $82: 1161$

24. Lehman, J. S., and Shaner, G. 1996. Genetic variation in latent period among isolates of Puccinia recondita $\mathrm{f}$. sp. tritici on partially resistant wheat cultivars. Phytopathology 86:633-641.

25. Long, D. L., and Kolmer, J. A. 1989. A North American system of nomenclature for Puccinia recondita f. sp. tritici. Phytopathology 79:525529.

26. Merrick, M. J. 1976. Hybridisation and selection for penicillin production in Aspergillus nidulans-A biometrical approach to strain improvement. Pages 229-242 in: Genetics of Industrial Microorganisms. K. D. MacDonald, ed. Academic Press, New York.

27. Milus, E. A., and Line, R. F. 1980. Characterization of resistance to leaf rust in Pacific Northwest wheats. Phytopathology 70:167-172.

28. Nyquist, W. E. 1991. Estimation of heritability and prediction of selection response in plant populations. Crit. Rev. Plant Sci. 10:235-322.

29. Ohm, H. W., and Shaner, G. E. 1976. Three components of slow leaf-rusting at different growth stages of wheat. Phytopathology 66:1356-1360.

30. Papa, K. E., Srb, A. M., and Federer, W. T. 1966. Selection for increased growth rate in inter- and intra-strain crosses of Neurospora. Heredity 21 : 595-613.

31. Parlevliet, J. E., and Kuiper, H. J. 1985. Accumulating polygenes for partial resistance in barley to barley leaf rust, Puccinia hordei. I. Selec- tion for increased latent periods. Euphytica 34:7-13.

32. Pateman, J. A. 1955. Polygenic inheritance in Neurospora. Nature (Lond.) 176:1274-1275.

33. Schafer, J. F. 1987. Rusts, smuts, and powdery mildew. Pages 542-584 in: Wheat and Wheat Improvement. E. G. Heyne, ed. 2nd ed. American Society of Agronomy, Madison, WI.

34. Shaner, G. 1973. Estimations of conidia production by individual pustules of Erysiphe graminis f. sp. tritici. Phytopathology 63:847-850.

35. Shaner, G. 1983. Growth of uredinia of Puccinia recondita in leaves of slow- and fast-rusting wheat cultivars. Phytopathology 73:931-935.

36. Shaner, G., Buechley, G., and Nyquist, W. E. Inheritance of latent period of Puccinia recondita in wheat. Crop Sci. In press.

37. Shaner, G., and Finney, R. E. 1980. New sources of slow leaf-rusting resistance in wheat. Phytopathology 70:1183-1186.

38. Shaner, G., Ohm, H. W., and Finney, R. E. 1978. Response of susceptible and slow leaf-rusting wheats to infection by Puccinia recondita. Phytopathology 68:471-475.

39. Simchen, G. 1966. Monokaryotic variation and haploid selection in Schizophyllum commune. Heredity 21:241-263.

40. Steel, J. G. D., and Torrie, J. H. 1980. Principles and Procedures of Statistics: A Biometrical Approach. 2nd ed. McGraw-Hill, New York.

41. Tervet, I. W., Rawson, A. J., Cherry, E., and Saxon, R. B. 1951. A method for the collection of microscopic particles. Phytopathology 41:282-285. 